\title{
Liquefaction perspective of soil ageing
}

\author{
I. TOWHATA*, Y. TAGUCHI†, T. HAYASHIDA $\uparrow$, S. GOTO,+ Y. SHINTAKU§, \\ Y. HAMADA§ and S. AOYAMA\|
}

\begin{abstract}
Subsoil liquefaction during strong earthquakes is one of the major seismic threats to the human community. Over the past few decades various methodologies have been proposed to assess liquefaction vulnerability; however, recent seismic events in Japan have revealed that current assessment methods are over conservative, which results in unnecessarily higher costs in mitigation measures. To overcome this situation, this study reinterprets the dynamic behaviour of sandy subsoils subject to recent and historical ground motions from Japanese seismic events and is able to demonstrate that aged soils have a higher liquefaction resistance than suggested by current design codes. Laboratory tests were also devised and conducted to study the mechanism of soil ageing at the particle scale level. Grain dislocations were observed to take place over time while boundary stress conditions maintained constant. These dislocations erased big voids, promoted a more stable granular structure and have the potential to give rise to greater liquefaction resistance.
\end{abstract}

KEYWORDS: earthquakes; liquefaction; microscopy; particle-scale behaviour; reclamation

\section{INTRODUCTION}

Sand liquefaction has become an important topic of geotechnical engineering since the 1960s and significant efforts have been made on the assessment of liquefaction resistance of in situ soils. The current methodology for this assessment commonly relies on in situ measurements such as SPT- $N$ (number of blows for $30-\mathrm{cm}$ penetration in standard penetration tests; Seed \& Idriss (1982) and Tatsuoka et al. (1980)).

Case histories indicate that most of the damaging liquefaction disasters occurred in geologically very young, sandy deposits, such as those found in manmade islands, former river channels, filled lakes, swamps and so on (Youd \& Perkins, 1978; Wakamatsu, 2000), as well as pipeline backfill. For example, during the 1964 Niigata earthquake, significant liquefaction occurred in the Kawagishi-cho area where the sandy ground had been constructed by pouring dune sand into water in the 1920s. Thus, the age of the liquefied ground was around 40 years at the time of the earthquake. Kobe Port Island, which developed significant liquefaction in 1995, was constructed by dumping gravelly sand into the sea in the late 1960 s and 1970s. Thus, the age of liquefied soil was about 30 years or less. During the 2011 gigantic Tohoku earthquake in eastern Japan, liquefaction in the Tokyo Bay area occurred predominantly in recent manmade islands (Towhata et al., 2014). As those islands were constructed after the late 1960s, the age of soil was around 40 years. Fig. 1 illustrates the distribution of liquefaction in Urayasu City on the Tokyo Bay. Here, the land in the liquefied areas was constructed after the 1960s, whereas the ground in the liquefaction-free areas such as 'Nekozane' and 'Todaijima' had been in place

Manuscript received 8 March 2015; revised manuscript accepted 25 October 2016. Published online ahead of print 22 December 2016.

Discussion on this paper closes on 1 November 2017, for further details see p. ii.

Published with permission by the ICE under the CC-BY license.

(http://creativecommons.org/licenses/by/4.0/)

* University of Tokyo, Tokyo, Japan.

$\dagger$ Fudo-Tetra Corporation, Tokyo, Japan.

+ Waseda University, Tokyo, Japan.

§ Formerly University of Tokyo, Tokyo, Japan.

|| Kisojiban Consultants, Tokyo, Japan.
200 years ago according to Tadataka Inoh's map, which was based on modern survey technology at the beginning of the nineteenth century (Fig. 2). As both the liquefied and unliquefied areas possessed very similar SPT- $N$ values (Fig. 3), it is evident that liquefaction vulnerability assessment can be improved by accounting for the age of the deposit. However, age is not generally considered in current practice, and in situ penetration resistance is solely relied on.

\section{PREVIOUS STUDIES ON AGEING OF SOIL}

Ageing is the change of material properties which occurs over time. Although geological ageing lasts for thousands to millions of years, the present paper addresses engineering ageing of a shorter timescale, such as a few days to 100 years (Schmertmann, 1991), over which such soil properties as SPT- $N$ and liquefaction resistance have been known to increase.

Youd \& Hoose (1977) together with Seed (1979) stated that most liquefaction during earthquakes occurs in 'young' subsoil. Youd \& Perkins (1978) qualitatively stated that cohesionless sediments younger than 500 years old have higher susceptibility to liquefaction than older soils. Arango et al. (2000) conducted liquefaction tests on undisturbed aged sand to show that the liquefaction resistance of Miocene sand is greater than what is suggested by design formulae developed for Holocene sands. However, most studies on ageing are limited to Pleistocene or older sands, and not much information is available on more recent soils, and particularly on those younger than 1000 years old. Lewis et al. (2008) tested undisturbed samples and demonstrated the higher liquefaction resistance of soils with ages of 5 to 23 million years. For a quantitative study on ageing, Leon et al. (2006) discussed the timescale of thousands of years or more on the basis of a small number of available data. Yoshimi et al. (1984), Goto (1995), Goto et al. (1987, 1992), Hatanaka et al. (1985, 1988), Hori et al. (2002) and Nagase et al. (1999) employed undisturbed frozen samples, whereas Seki et al. (1992) conducted block sampling, to compare the liquefaction resistance of aged soil with laboratoryreconstituted (young) specimens. Mulilis et al. (1977) studied several sites to show the increase of liquefaction resistance 


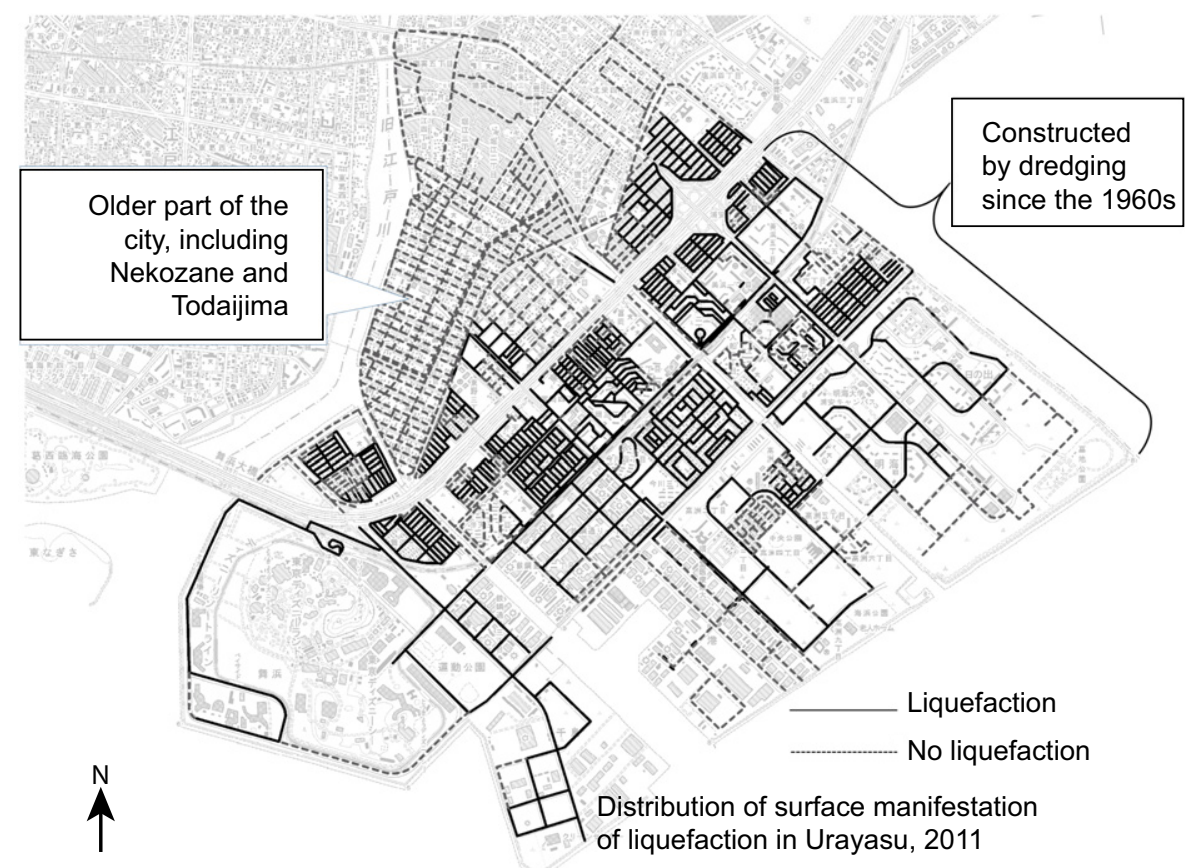

Fig. 1. Distribution of liquefaction sites in Urayasu City

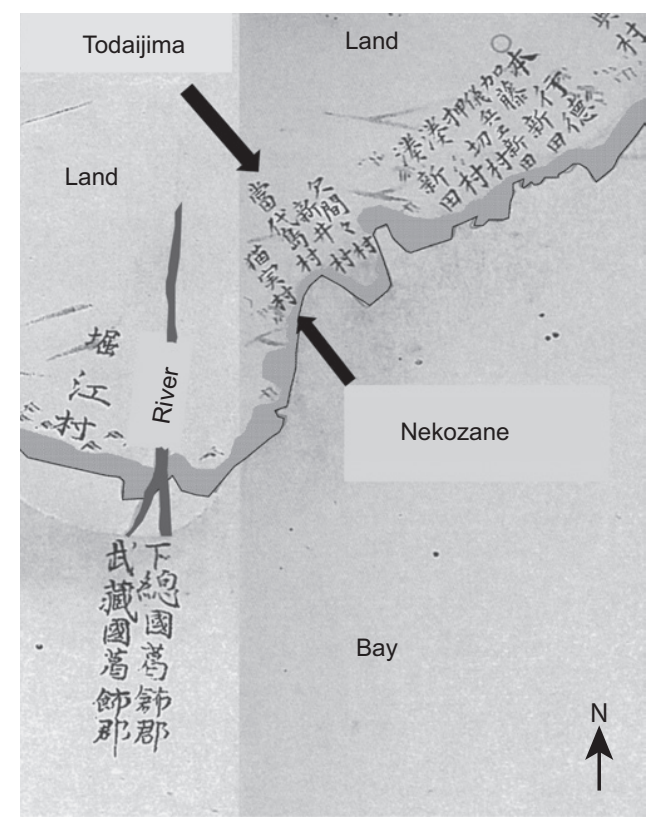

Fig. 2. Urayasu in Inoh's map that was published in 1804 (English explanation was written after black-and-white processing of the original Inoh's map)

over thousands of years. Hayati \& Andrus (2009) interpreted many reports on laboratory tests and field interpretations to propose an empirical formula for the effect of ageing. The authors note that, although there have been several US studies on aged soils, these have involved ages greater than 10000 years (e.g. Heidari \& Andrus, 2012) and there are very few data available on soils aged within the engineering timescale of interest in this paper of 100 to 1000 years.

Current practice assesses the liquefaction resistance predominantly by SPT- $N$ values. Hence, if both $\mathrm{SPT}-N$ value and liquefaction resistance increase with time at the same rate, there would be no further need to consider the effect of ageing on liquefaction vulnerability. Fig. 3 compares SPT- $N$

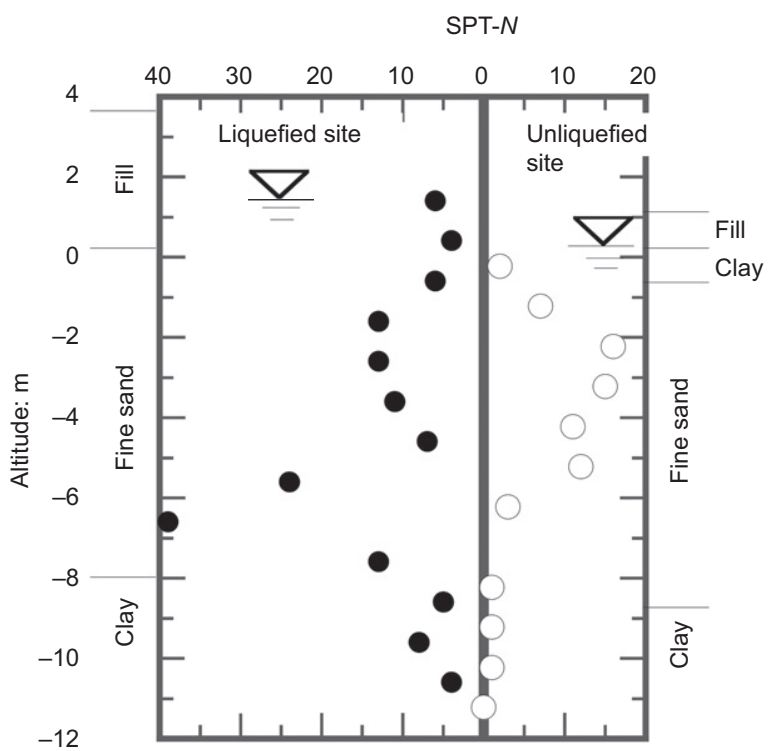

Fig. 3. Comparison of borehole data between liquefied and unliquefied sites in Urayasu City (drawn by using data from Geotechnical and Geoenvironmental Data Bank of Chiba Prefecture)

profiles at a young liquefied site and an unliquefied site of greater age that was shaken by the 2011 Tohoku earthquake (moment magnitude $M_{\mathrm{w}}=9 \cdot 0$ ) in Urayasu, Japan. Although both sites have similar SPT- $N$ values in the top $2-3 \mathrm{~m}$ of the fine sandy layer, liquefaction damage was found only at the site of the most recent deposits. In line with this, Matsuo (2004) stated that aged alluvial sand is systematically more resistant to liquefaction than recently deposited manmade islands, even if normalised $N_{1}$ values are identical. Although Skempton (1986) suggested the increase of SPT- $N$ over 100 years, Mesri et al. (1990), Baxter \& Mitchell (2004), Mitchell \& Solymer (1984) and Massarsch \& Fellenius (2002) stated that the increase of SPT- $N$ or CPT (cone penetration test) resistance is completed within 1 year after land construction or significant compaction. This short-term 
increase of SPT- $N$ value implies that the ageing of SPT- $N$ cannot account for the observed improvement in liquefaction resistance that occurs over a timescale of hundreds or thousands of years. Roy (2008) mentioned that CPT resistance increases with age more slowly than $\mathrm{S}$ wave velocity.

In Fig. 4, the horizontal axis designates the elapsed time after liquefaction and fresh deposition of sand grains, and the vertical axis shows the increment of SPT- $N$ value after fresh deposition. The increment was calculated from the pre-liquefaction SPT- $N$. In the tests by Kiyota and quoted by Towhata et al. (2012), the pre-liquefaction grain structure was destroyed by liquefaction during the 2011 Tohoku earthquake and grains redeposited to form a new structure. In Kusunoki et al. (2013), blast-induced liquefaction destroyed the original grain structure and a new one was created. In both cases, the penetration resistance was measured by Swedish weight sounding at practically the same places for 900 days and was converted to equivalent SPT- $N$ values using a formula by Inada (1960). Penetration resistance increased for a short period of only 1 year after fresh deposition.

Figure 5 presents schematically the authors' concept of ageing that SPT- $N$ and liquefaction resistance of soil $(R)$ increase with time at different rates. After some elapsed time the real liquefaction resistance becomes substantially greater than what increased SPT- $N$ implies and thus a quantitative study is necessary on the additional liquefaction resistance produced by ageing.

Laboratory tests were conducted by Mulilis et al. (1977) and Tatsuoka et al. (1988) on sand with different consolidation times. Although the employed consolidation time was limited to several months owing to the experimental constraints, the liquefaction resistance increased by, at maximum, $40 \%$ or so from that of the freshly deposited samples.

Past studies on the causative mechanisms of engineering ageing are classified into two groups. The first group

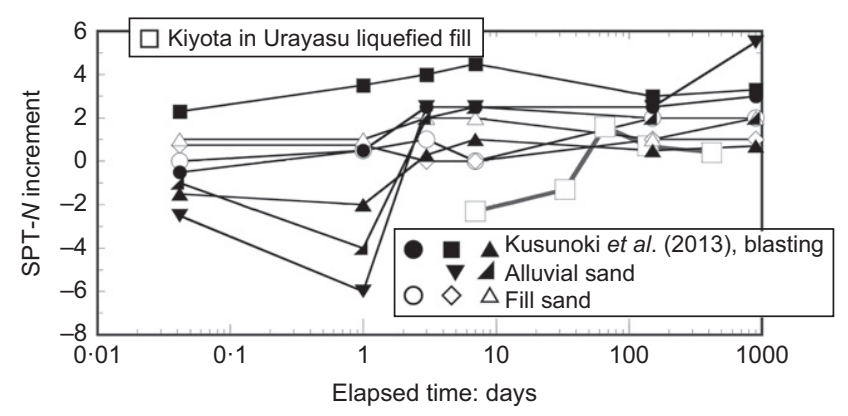

Fig. 4. Increase of penetration resistance with time

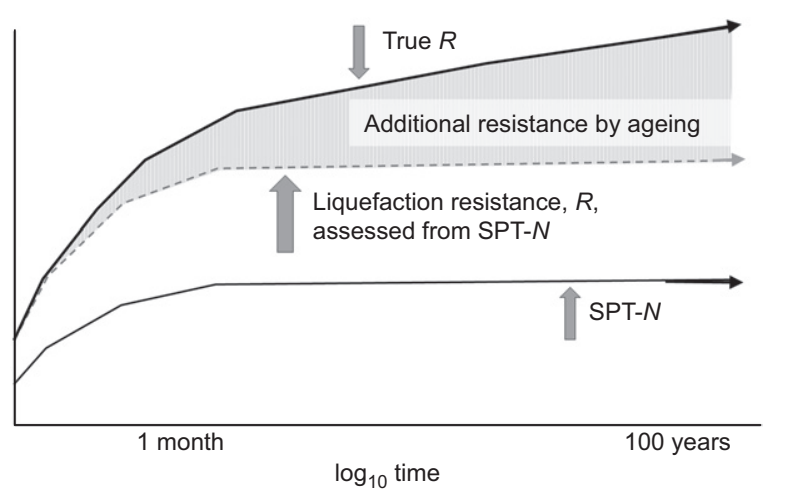

Fig. 5. Schematic diagram of rates of SPT- $N$ increase and improvement of liquefaction resistance $(R)$ addresses cementation (e.g. Kokusho et al., 2012). As the bonding mechanism, Mitchell \& Solymer (1984) proposed sedimentation of silicate material at granular contacts for which the silicate material is supplied from soil grains. The second idea concerns the change of granular packing induced by weak ground vibrations and so on (Wichtmann et al., 2005; Kiyota et al., 2009; Kondo, 2013; Dobry et al., 2015). The authors suppose that the induced dislocation of sand grains fills big voids, improves the mechanical stability of fabric structures, intergranular locking or the number of grain contacts and increases the liquefaction resistance. So far, no conclusion has been drawn on which mechanism is more predominant.

The present paper aims to shed more light on the ageing of geologically young soils. Although Towhata et al. (2015) briefly addressed the framework of this study, the page limitation did not allow any details to be introduced regarding the hypotheses employed and the idea on the causative mechanism of ageing. In this regard, the present paper provides more details to offer readers a better understanding.

\section{EXAMINATION OF AGEING IN TOKYO BAY AREA}

This section describes the authors' quantitative study on ageing that evolves over hundreds of years (briefly reported by Towhata et al. (2014)), focusing on reclaimed land in the Tokyo Bay area which suffered significant liquefaction damage in 2011. The Tokyo Bay area benefits from a comprehensive historical record of land reclamation since the end of the sixteenth century (Fig. 6). Information relating to incidents of liquefaction in this area during the 2011 Tohoku earthquake is available (Fig. 1). Additionally, the ground motion records for the region in 2011 are also available from K-Net stations. The wealth of available information allows the liquefaction resistance of sites within the Tokyo Bay area to be assessed using the Highway bridge design code (JRA, 2012) or the Recommendations for design of building foundations (Tokimatsu \& Yoshimi, 1983; AIJ, 2001). For example, the highway bridge design code assesses the effects of SPT- $N$, the effective vertical stress prior to shaking $\left(\sigma_{\mathrm{v}}^{\prime}\right.$ in $\mathrm{kPa})$ and the fines content $\left(F_{\mathrm{c}}\right)$ on the liquefaction resistance of loose sand $(R)$ undergoing strong ground motions that occur at the boundary of tectonic plates using equation (1)

$$
R=0.0882 \sqrt{C_{1} \frac{100 N}{\sigma_{\mathrm{v}}^{\prime}+70}+\frac{C_{2}}{1 \cdot 7}}
$$

In case of $F_{\mathrm{c}}<10 \%, C_{1}=1$ and $C_{2}=0$ when the normalised SPT- $N$, which is defined by $N_{1}=\left[170 N /\left(\sigma_{\mathrm{v}}^{\prime}\left(\mathrm{kN} / \mathrm{m}^{2}\right)+70\right)\right]$, is less than 14. Note that $\sigma_{\mathrm{v}}^{\prime}$ stands for the effective vertical stress prior to the application of earthquake loads and that $C_{1}$ and $C_{2}$ increase with $F_{\mathrm{c}}$. For reference, these two codes are compared with US practice in the Appendix.

The seismic load $(L)$ is assessed using the K-Net surface ground motion records, which allow the factor of safety, $F_{\mathrm{L}}=R / L$, to be determined and examined against the field observations of liquefaction incidents with reference to the soil age group. This would allow the boundary value of $F_{\mathrm{L}}$ between liquefaction and non-liquefaction to be determined taking into account soil age. Note that the boundary value should be equal to unity, but its real value probably changes with soil age.

The present study encountered many inevitable uncertainties, as described below.

(a) At sites where evidence of liquefaction such as sand ejecta or subsidence of buildings was observed, it is not always possible to identify which soil stratum liquefied 


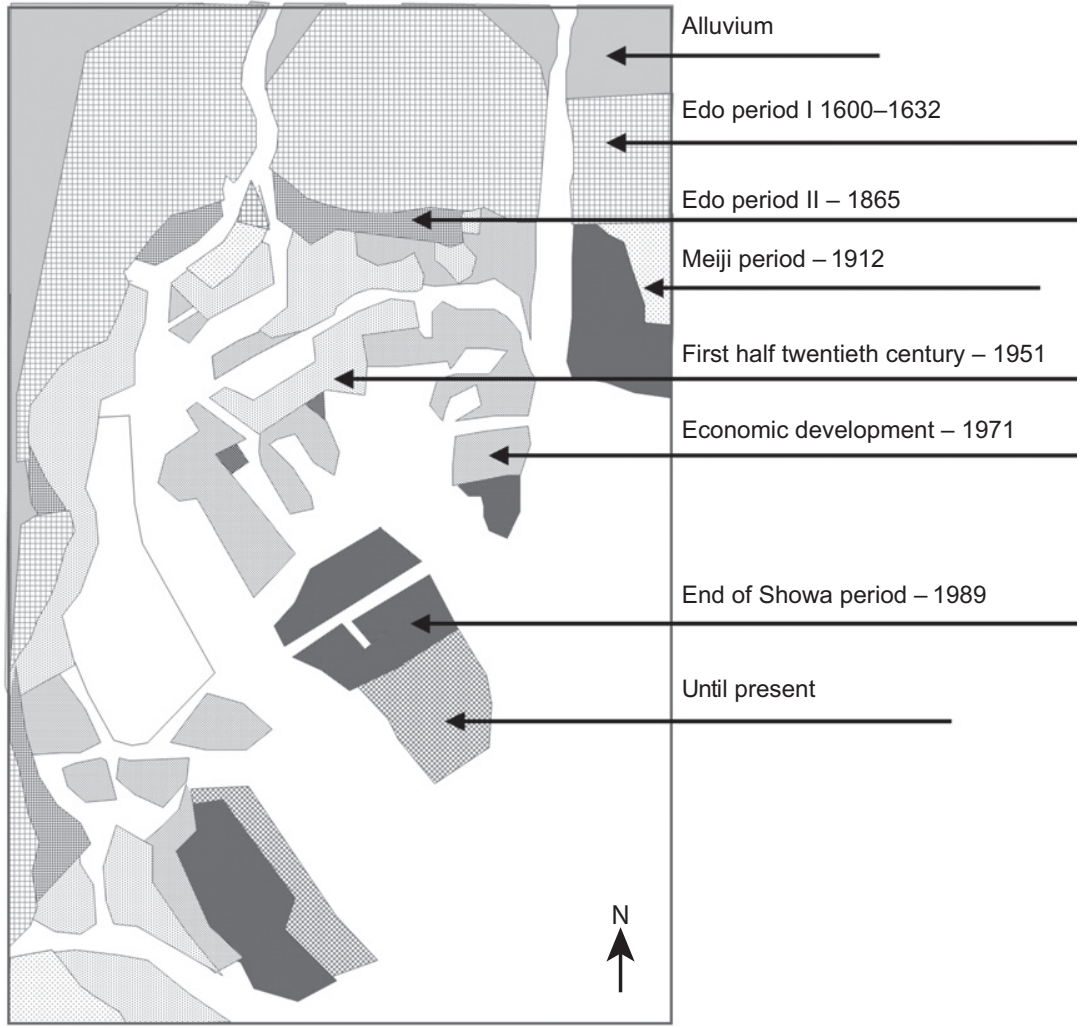

Fig. 6. History of land reclamation in the Tokyo Harbour and adjacent areas (drawn after the Kanto Regional Development Bureau, the Ministry of Land, Infrastructure, Transport and Tourism)

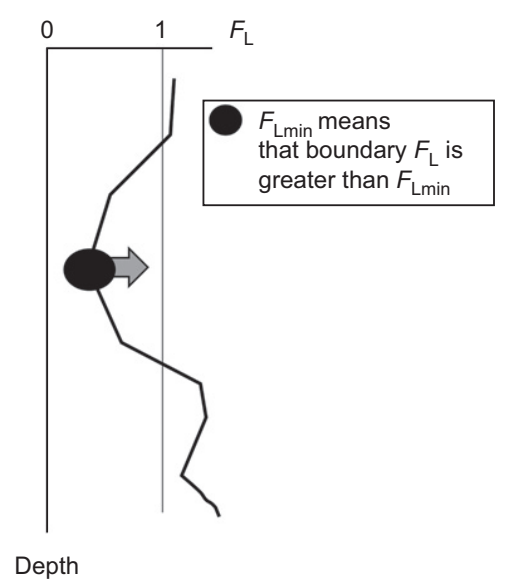

(a)

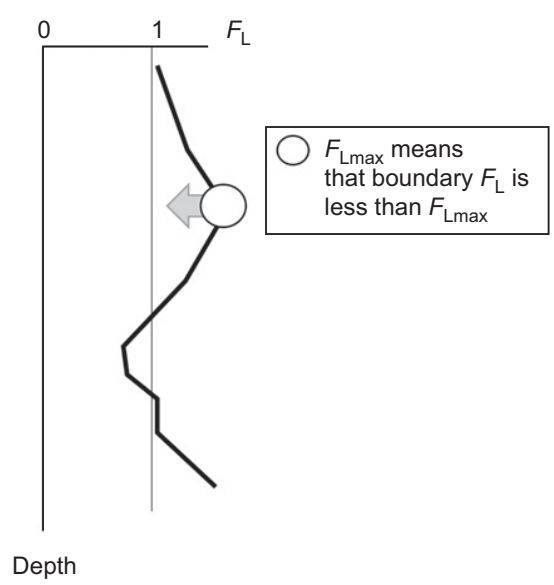

(b)

Fig. 7. Methodology to evaluate the boundary value of $F_{\mathrm{L}}$ between liquefaction and non-liquefaction: (a) liquefied site; (b) unliquefied site

unless the $F_{\mathrm{L}}$ method is precise. Because the present study attempts to improve the $F_{\mathrm{L}}$ method by taking into account soil age, $F_{\mathrm{L}}$ cannot be considered precise.

(b) At sites without observable surface manifestation of liquefaction, it is possible that soils at greater depths liquefied without affecting the ground surface.

(c) The majority of K-Net stations are situated on unliquefied sites.

(d) Sites of K-Net stations and those of analysed borehole data are not necessarily identical and the $F_{\mathrm{L}}$ values have to be calculated by using the nearest available K-Net data.

(e) Alluvial deposits are generally assumed to be older than reclaimed manmade islands. However, in the extreme case, it is possible that deposition occurred in the past few hundred years.

( $f$ ) Liquefaction can occur in more recent backfill of lifelines within much older natural deposits.

Bearing these uncertainties in mind, the present study employed a conservative approach to avoid significant misinterpretation. Cases of liquefaction of lifeline backfill were removed from the dataset.

Figure 7 illustrates the method employed to reduce the impact of uncertainties $(a)$ and $(b)$. At liquefaction sites, $F_{\mathrm{L}}$ was calculated and plotted in Fig. 7(a) for the entire soil profile that consists of the surface artificial fill and the underlying alluvial sand. In this figure, it is not yet clear which sandy layer liquefied and which did not. However, the surface 
evidence of liquefaction ensures that liquefaction occurred somewhere in the profile (Fig. 7(a)). Therefore, the boundary value of $F_{\mathrm{L}}$ between liquefaction and non-liquefaction is greater than the minimum value, $F_{\mathrm{Lmin}}$, in the profile. This is because, if the boundary value were less than $F_{\mathrm{Lmin}}, F_{\mathrm{L}}$ would be greater than the boundary value at all depths and no liquefaction could have occurred in the entire soil profile, which contradicts the observation. On the contrary, at sites without manifestation of liquefaction, the boundary value of $F_{\mathrm{L}}$ is less than the maximum value, $F_{\text {Lmax }}$ (Fig. 7(b)). Otherwise, $F_{\mathrm{L}}$ would be less than the boundary value at all depths and liquefaction could have occurred in the entire soil profile, which is against the observation. Consequently, the range of the boundary $F_{\mathrm{L}}$ is determined as

$$
F_{\text {Lmin }}<\text { Boundary } F_{\mathrm{L}}<F_{\text {Lmax }}
$$

Four hundred and fifty borehole profiles were collected from many databases in eastern Tokyo and adjacent areas and $F_{\mathrm{L}}$ profiles such as that shown in Fig. 7 were calculated using the Highway bridge design code of Japan. Note that all the employed borehole data were obtained prior to the 2011 earthquake. $F_{\text {Lmax }}$ and $F_{\text {Lmin }}$ were then assessed from the profiles and plotted against the era of land reclamation. The year of land reclamation can only be approximately determined owing to the limited accuracy of the available historical information and because the process of reclamation takes many years. Furthermore, although it is assumed that the alluvial soil is older than manmade ground, this may not always be the case $(e)$. Accordingly, in Fig. $8, F_{\text {Lmax }}$ is plotted with downward arrows because the boundary value is less than $F_{\text {Lmax }}$ (equation (2)). Conversely, $F_{\text {Lmin }}$ is plotted with upward arrows because the boundary is greater than $F_{\mathrm{Lmin}}$. Hence, the desired boundary values should lie between the upward and downward arrows.

The shaded area in Fig. 8 indicates the possible range of boundary $F_{\mathrm{L}}$. It is interesting that the suggested boundary decreases as the soil becomes older, implying that the greater the age of the soil, the less likely it is to liquefy despite $F_{\mathrm{L}}$ being less than unity. As the measured SPT- $N$ values were employed in the calculation, the idea of additional increase

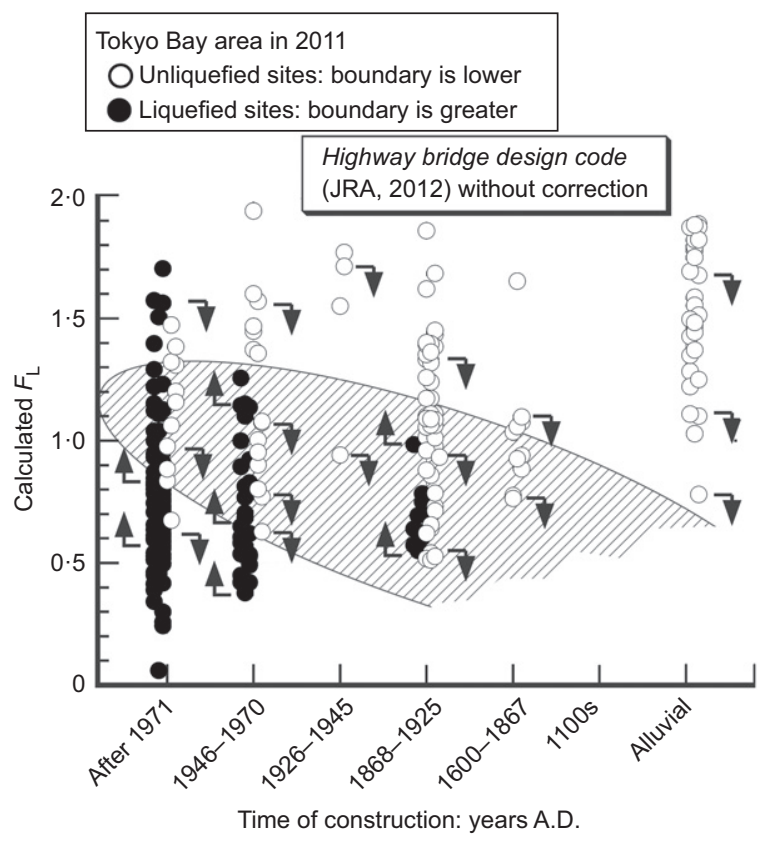

Fig. 8. First assessment of boundary $F_{L}$ between liquefaction and non-liquefaction by using the method of the Highway bridge design code (JRA, 2012) of liquefaction resistance (Fig. 5) can be examined whether SPT- $N$ becomes constant after a short time (Fig. 6) or possibly keeps increasing. Also, care must be taken of the very wide range of the shaded area that was caused by uncertainties of $(c)$ and $(d)$. The uncertainty of $(e)$ was solved in the Urayasu City by referring to the old map by Tadataka Inoh as stated previously. Moreover, the boundary value of the youngest soil is greater than unity, which is not consistent with the theory of factor of safety.

In order to improve Fig. 8, three measures were taken, as listed below.

(a) The 2011 Tohoku earthquake had a seismic magnitude of 9.0 and generated an unusually large number of shaking cycles (Fig. 9), which was able to promote the development of excess pore water pressure more profoundly than the 15 to 20 cycles considered in conventional design codes. This situation was exacerbated by a strong aftershock of magnitude $\left(M_{\mathrm{w}}\right)=7 \cdot 7$ that occurred 30 min after the main shock. Thus, $F_{\mathrm{L}}$ was reduced by $20 \%$, by which both the significant number of cycles in $M=9 \cdot 0$ main event and that of the smaller aftershock are considered. Yasuda \& Ishikawa (2012) proposed a reduction of $18 \%$. Note that the Highway bridge design code does not require the earthquake magnitude for input, whereas the building foundation code of Japan does.

(b) Noting that $F_{\mathrm{L}}$ in Fig. 8 was calculated using the biggest value of the east-west and north-south peak accelerations, the effect of the bi-directional shaking, $\sqrt{E W^{2}+N S^{2}}$, was absent. In order to account for the reduction in liquefaction resistance due to superposition of the components of strong motion (Seed et al., 1978), the calculated $F_{\mathrm{L}}$ value was reduced by $10 \%$; Ishihara \& Yamazaki (1980).

(c) The acceleration records employed in Fig. 8 were obtained at K-Net sites where liquefaction did not occur (uncertainty $(c)$ ). Because of the softer soil, the acceleration at liquefied sites was most likely greater than the K-Net records (amplification by soft soil). For example, Fig. 10 compares the K-Net acceleration in Urayasu and those obtained in the reclaimed and liquefaction-prone land of the same city, all at similar epicentral distances. Moreover, data at the K-Net Inagi site, which liquefied, are added. Peak accelerations at sites of (significant) liquefaction were greater than that at the unliquefied K-Net site (see 1:1 line). The range of data variation is substantial owing to many underlying uncertainties. With some conservatism, the maximum acceleration at the K-Net site is multiplied by $4 / 3$ to assess the near-upper-bound values of accelerations in liquefaction-prone sites. Thus, the factor of safety, $F_{\mathrm{L}}$, was reduced to $3 / 4$ at sites of liquefaction. In summary, the previously calculated $F_{\mathrm{L}}$ values were

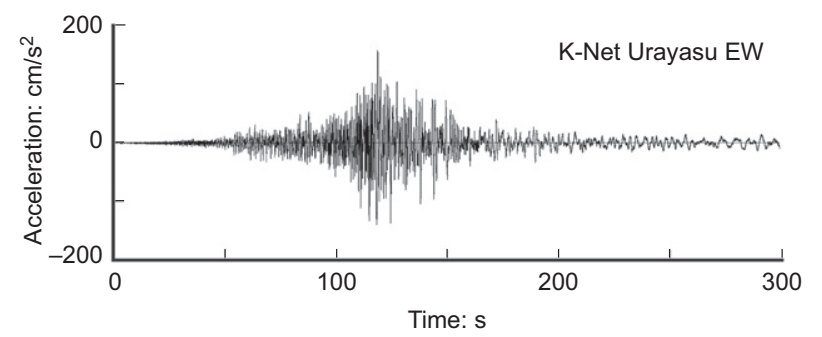

Fig. 9. Acceleration-time history as observed at K-Net Urayasu station 


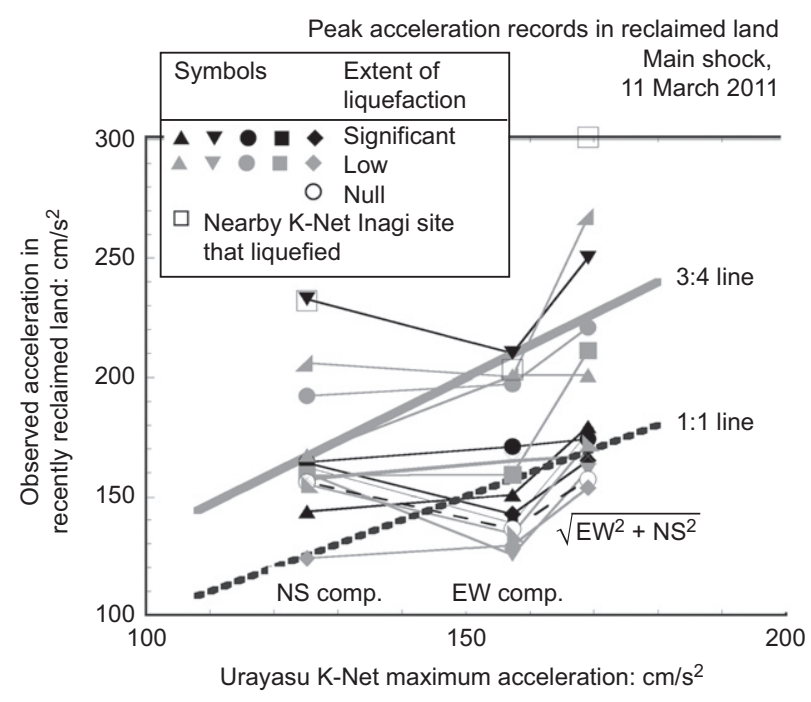

Fig. 10. Comparison of K-Net records on unliquefied ground and those upon liquefaction-prone reclaimed land in the same city (note that the extent of liquefaction at those sites is based on the authors' reconnaissance survey but is not perfectly correct because of the heterogeneous nature of subsoil)

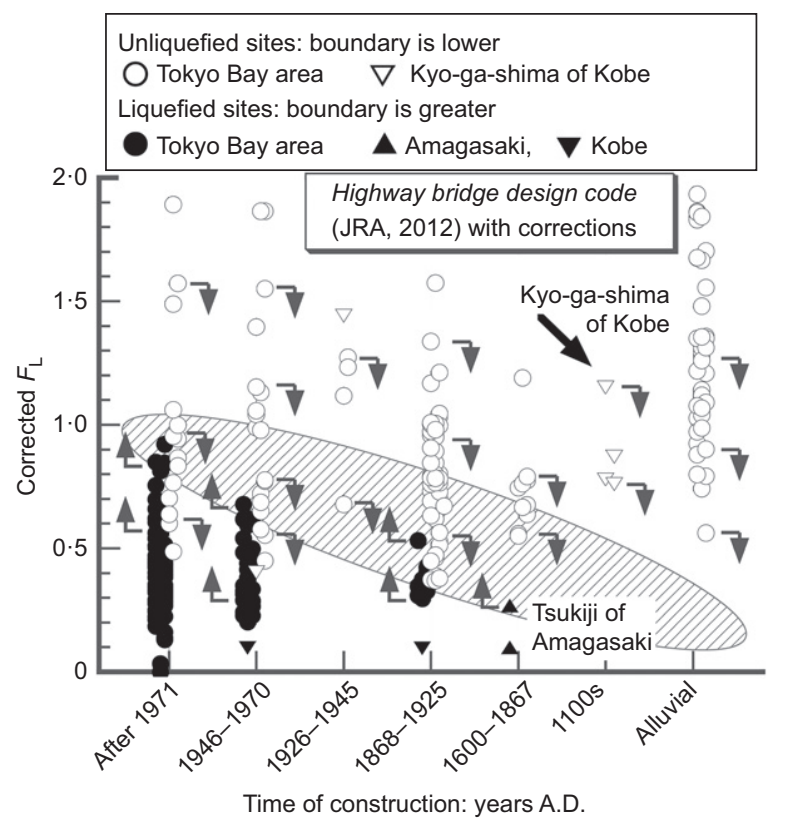

Fig. 11. Improved assessment of boundary $F_{\mathrm{L}}$ between liquefaction and non-liquefaction by using the method of the Highway bridge design code (JRA, 2012)

modified by multiplying by $0.8 \times 0.9 \times(3 / 4)$ or $0 \cdot 8 \times 0 \cdot 9$, depending upon liquefaction or no liquefaction at respective sites.

The modified result (Fig. 11) clearly demonstrates a reduction of the range of uncertainty in the boundary $F_{\mathrm{L}}$ values compared to Fig. 8 and younger deposits have the boundary values of unity, which is consistent with design practice. The new data from Amagasaki and Kyo-ga-shima and other sites in Kobe will be discussed in the later sections. It is noteworthy that more aged soils were unlikely to liquefy in spite of the small values of $F_{\mathrm{L}}$. This implies that the true resistance of older soils is greater than that assumed by the current design codes without considering soil age.

\section{LIQUEFACTION IN TSUKIJI AREA IN \\ AMAGASAKI CITY IN 1995}

The data from the 2011 Tohoku earthquake were limited to the Tokyo Bay area where the age of liquefied sites was, at maximum, 100 years or so. Therefore, data on older liquefied sites were sought. The requirements for reliable data are

(a) evidence of the onset of or lack of liquefaction

(b) availability of borehole data

(c) availability of earthquake records at or near the studied borehole sites

(d) known age of subsoil.

These requirements were satisfied by the Tsukiji area in Amagasaki City and Kyo-ga-shima Island, Kobe.

\section{Liquefaction in Tsukiji area in Amagasaki city in 1995}

The Tsukiji area in Amagasaki City (Fig. 12) was constructed in shallow sea in front of the Amagasaki Castle at the beginning of the seventeenth century and suffered significant liquefaction during the 1995 Kobe earthquake of $M_{\mathrm{w}}=6.9$. The land reclamation started in 1617 and was completed by the middle of the seventeenth century. Hence, the age of the reclaimed subsoil at Kobe earthquake was approximately 400 years.

A typical borehole profile in Tsukiji is illustrated in Fig. 13. The earthquake motion record was obtained by the Ministry of Transport in the Amagasaki Harbour and its peak acceleration value was input to the liquefaction analysis. The obtained $F_{\text {Lmin }}$ was $0 \cdot 147$. Only $(b)$ and $(c)$ measures were employed to improve the calculated $F_{\mathrm{L}}$ value, while (a) was not, as the number of cycles generated by the Kobe earthquake was within the range of consideration of the present design codes. Consequently, $F_{\text {Lmin }}=0.099$ was plotted by a solid dot as an older soil in Fig. 11.

\section{Investigation on older manmade island}

Kyo-ga-shima Island was constructed near the end of the twelfth century in the present Kobe Harbour by Taira-no-Kiyomori, who intended to construct an island in front of his harbour (Hyogo in Fig. 12) to protect international trading ships from southeast winds and waves. A classic descriptive poem 'Heike Monogatari' states that the construction started in 1161 and that the area of the island was 37 ha. Later, the knowledge of the exact location of this island was lost and the island is believed to be buried under more recent land reclamation activities. The most likely location of the ancient Kyo-ga-shima Island is the Hyogo area of Kobe (Fig. 14), which is the most traditional part of the Kobe Harbour and contains a number of historical cultural structures, such as old temples and statues. Strong ground motion of peak ground acceleration, $\mathrm{PGA}=616 \mathrm{~cm} / \mathrm{s}^{2}$ in the east-west direction was recorded at the nearby Takatori railway station, where no liquefaction was observed. Combined extensive borehole records for the area and good records of liquefaction locations satisfy data requirements $(a)$ to $(c)$.

The area in Fig. 14 is situated to the west of Hyogo Wharf, which was the main part of the Kobe Harbour until the nineteenth century. The authors interpreted a geotechnical borehole database as published by Kansai Geoinformatics Agency in order to identify precisely the location of Kyo-ga-shima. The island was constructed by transporting soils from local mountains into the sea. Because the local Rokko mountains are made of granite, the location of the missing island can be identified by a deposit of 


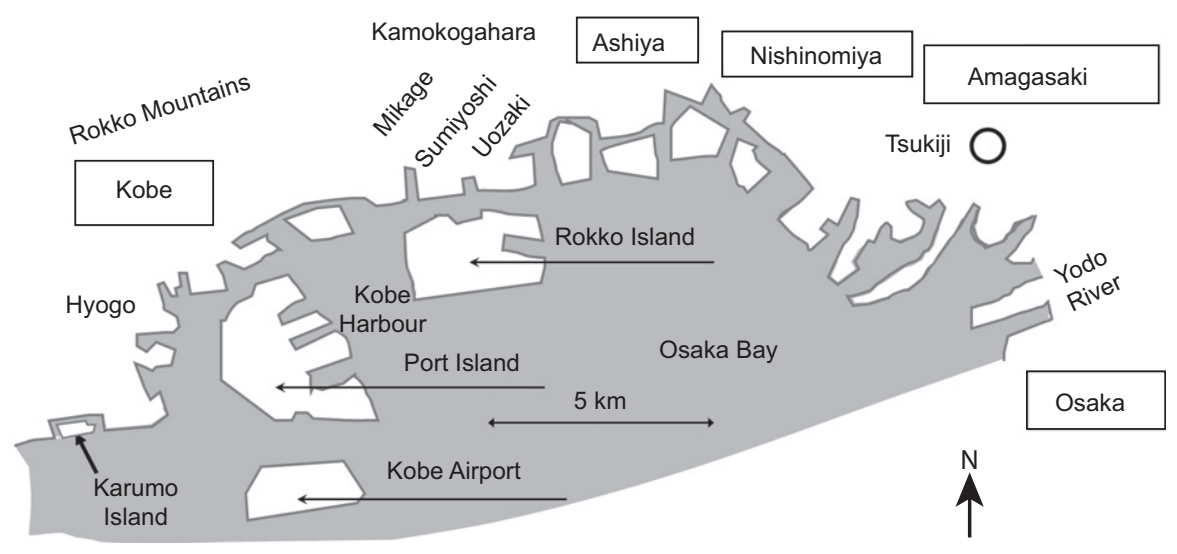

Fig. 12. Locations of Tsukiji of Amagasaki and Hyogo of Kobe

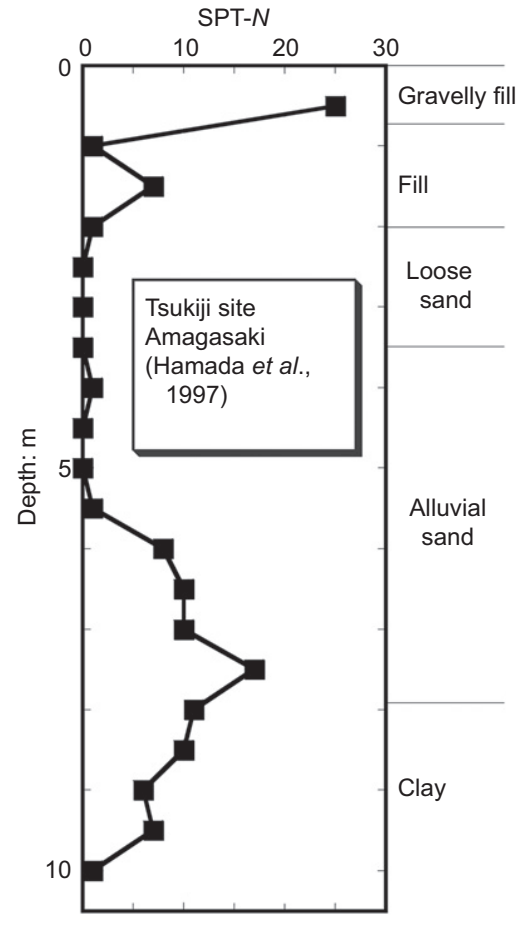

Fig. 13. One of the analysed borehole profiles in Tsukiji of Amagasaki (note: this profile was obtained after surface filling for reconstruction of the community after liquefaction damage)

gravelly-sandy materials lying above former seabed materials such as fine sand and silt.

After detailed investigations, cross-sections (Figs 14 and 15) pointed to the potential location of Kyo-ga-shima. Fig. 15 shows that a gravelly-sandy deposit lies on a layer of finer sand and silt. The separation of the gravelly mass from the underlying natural deposits of sand and silt suggests that it is an artificial deposit in a formerly inundated area. The convex shape of the sand-silt layer suggests consolidation settlement of the original seabed under the weight of the infill. Fig. 16 indicates the distribution of different soils at $-4 \mathrm{~m}$ below the sea level. A gravelly-sandy deposit at the centre shows the probable size of the ancient island, and the sand-silt deposit to its south suggests the entrance channel of the harbour. These findings mean that the location of the Kyo-ga-shima was most likely detected by the present study.

No liquefaction occurred in the ancient Kyo-ga-shima area (Wakamatsu, 2011). Thus, hollow circles $\left(F_{\text {Lmax }}\right)$ were drawn in Fig. 11 together with downward arrows. The studies at

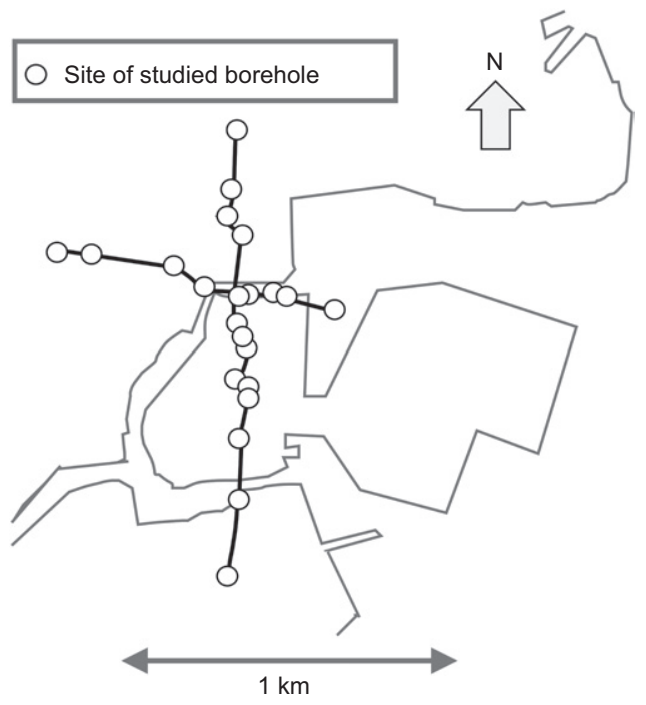

Fig. 14. Area of Kyo-ga-shima search

other sites in Kobe provided data on liquefied manmade islands (Karumo Island in Fig. 12 and others) that were constructed in the first half of the twentieth century and were nearly 100 years old at the time of the 1995 Kobe earthquake.

Consequently, Fig. 11 presents all data and evidently demonstrates that the boundary $F_{\mathrm{L}}$ value decreases with increasing age of soil. Thus, the older soil is unlikely to liquefy even though the calculated factor of safety, $F_{\mathrm{L}}$, is less than unity, and ageing produces additional resistance against liquefaction. But it is noteworthy that this ageing effect is not considered in the current SPT-based design codes and that the liquefaction resistance of aged soil is underestimated. Although Fig. 4 might suggest minor increase in SPT- $N$ for hundreds of years, this increase is not significant enough to account for ageing in liquefaction resistance. This is because the SPT-based $F_{\mathrm{L}}$ in aged soil is still less than unity, in spite of lack of liquefaction. Similar ageing was found from the Recommendations for design of building foundations (AIJ, 2001) as well (Fig. 17).

\section{INCREASE OF LIQUEFACTION RESISTANCE WITH AGE}

The boundary $F_{\mathrm{L}}$ values are able to quantitatively reveal the increase of liquefaction resistance with soil age. For example, if the boundary value is $0 \cdot 5$, the liquefaction 


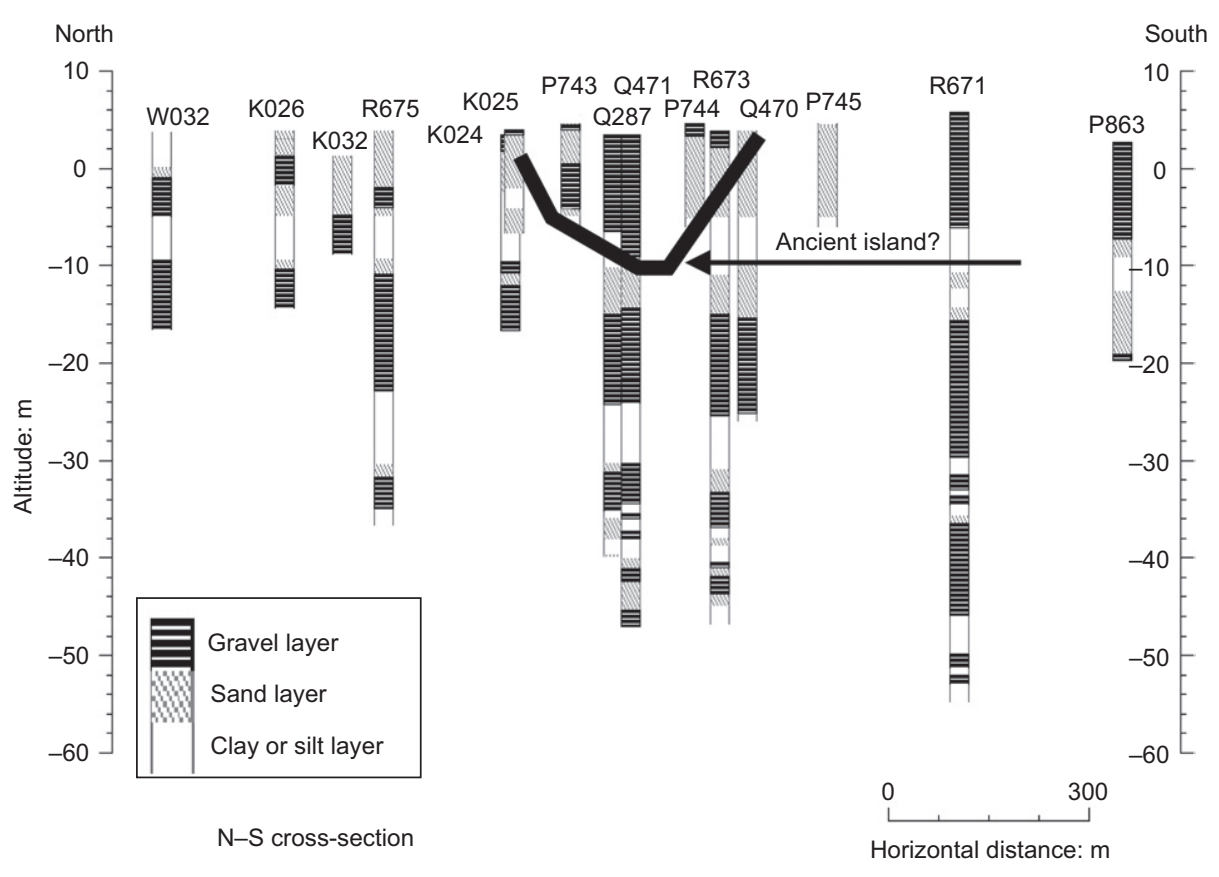

Fig. 15. Promising cross-sections of the ancient island

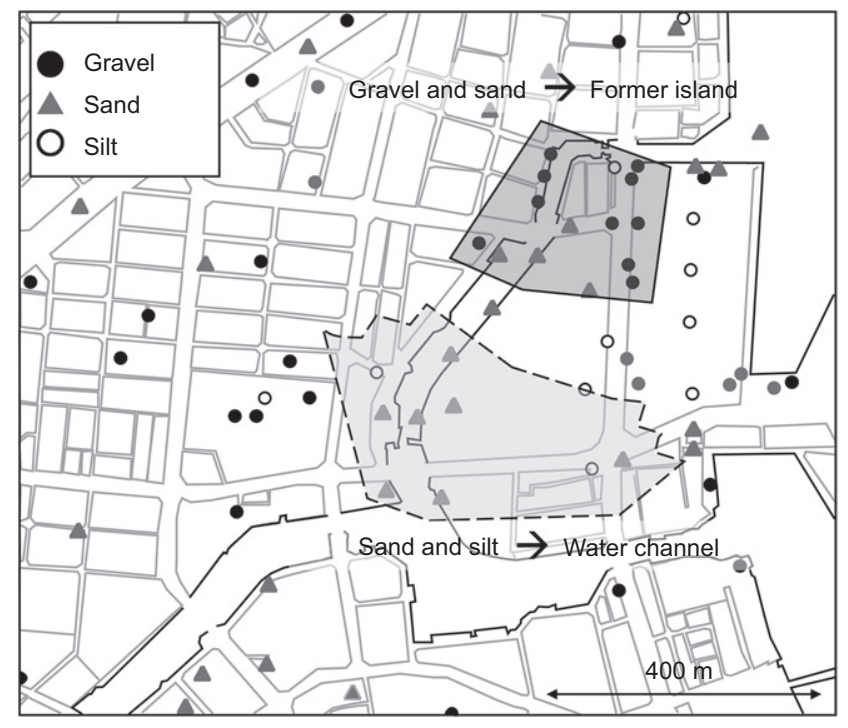

Fig. 16. Horizontal cross-section of local soils at $-4 \mathrm{~m}$ below the sea level

resistance is 2 times greater than the SPT-based design code calculation. By using the upper and lower bounds of the shaded area in Fig. 11, the ageing effect was quantitatively drawn in Fig. 18. The derived age-induced increase is consistent with the results of former studies obtained by undisturbed samples or other case history studies. Because the current design code calculation takes into account only the limited effect of temporal increase of SPT- $N$, the present study indicates the ratio of

$$
\left(\begin{array}{c}
\text { Effect of temporal increase of SPT }-N \text { and the extra } \\
\text { contribution of age }
\end{array}\right)
$$

(Effects of increased SPT $-N$ only)

whereas other studies on ageing consider the combined effects of increased SPT- $N$ and ageing, except field tests by

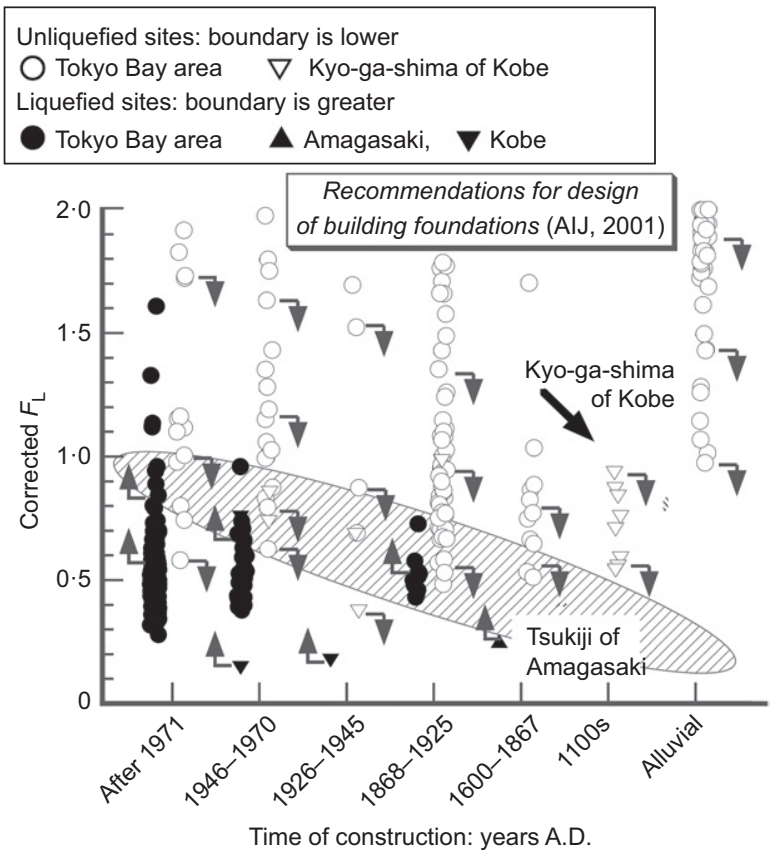

Fig. 17. Improved assessment of boundary $F_{\mathrm{L}}$ between liquefaction and non-liquefaction by using the method of the building design code (AIJ, 2001)

Hayati \& Andrus (2009) and Lewis et al. (2008) in Fig. 18. Note that studies by other researchers indicate an increase of more than $40 \%$ after 50 years or so, although the present study suggests a greater increase after 1000 years. Accordingly, it is possible herein to state with sufficient conservatism that the ageing becomes prominent after 100 years and that at least a $40 \%$ increase can be expected after 400 years.

\section{POSSIBLE MECHANISM OF AGEING IN LIQUEFACTION RESISTANCE}

To shed light on the causative mechanism of ageing, laboratory tests were conducted in which dislocation of sand 


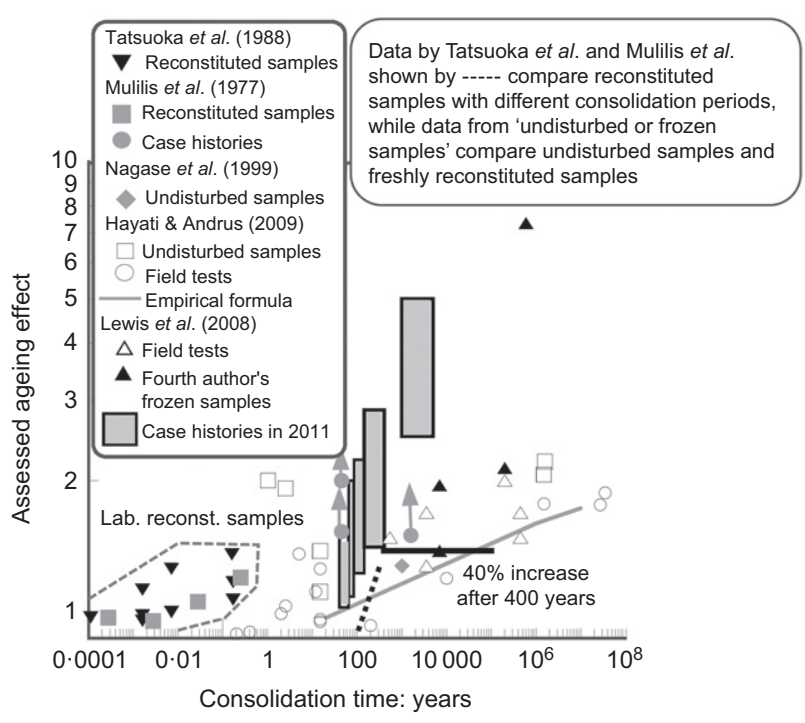

Fig. 18. Quantitative illustration of the increase of liquefaction resistance of soil with age

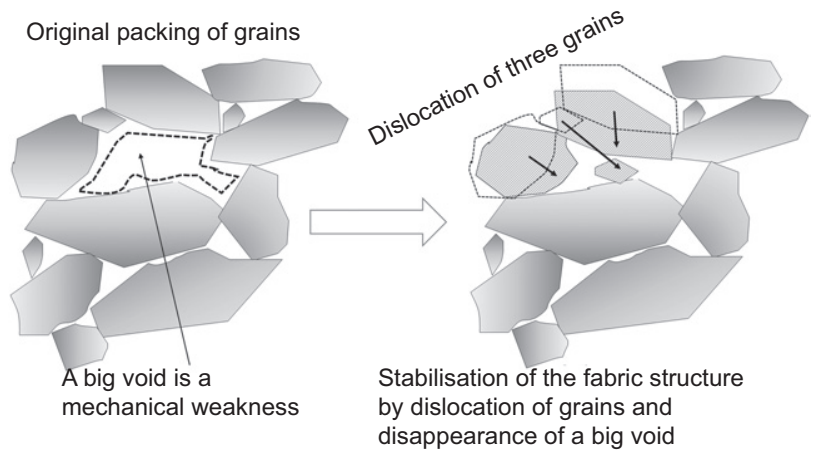

Fig. 19. Hypothesis on microscopic dislocation of sand grains and erased big void

grains under sustained pressure was observed microscopically (Shintaku \& Towhata, 2013). Although grain shape may be important and mineralogy may affect the development of cementation, the present paper focuses on a hypothesis that the dislocated sand grains generate more grain-to-grain contact points or fill big voids to create more interlocking and more uniform stress distribution so that the mechanical properties of sand as a mass may be improved (Fig. 19). The dislocation of one particle triggers that of the next grain and so on. This procedure occurs rather slowly and hence the improvement of the mechanical properties of sandy ground takes as long as hundreds of years.

\section{Test method}

Dry sand with different non-plastic fines content was placed by air pluviation in a soil tank that measured $6 \mathrm{~cm} \times 15 \mathrm{~cm} \times 20 \mathrm{~cm}$. Then the sand was compressed under $25 \mathrm{kPa}$. Photographs were taken of the vertical cross-section of the sand deposit through a transparent side wall of the tank by using a microscopic camera every day and compared with each other to see whether or not there was any movement of grains. The extent of dislocation was expressed by the number of moved particles per square millimetre.

\section{Tested material}

Three kinds of silica sand $\left(G_{\mathrm{s}}=2 \cdot 65\right)$ were used and grain size distribution was controlled by mixing several kinds of

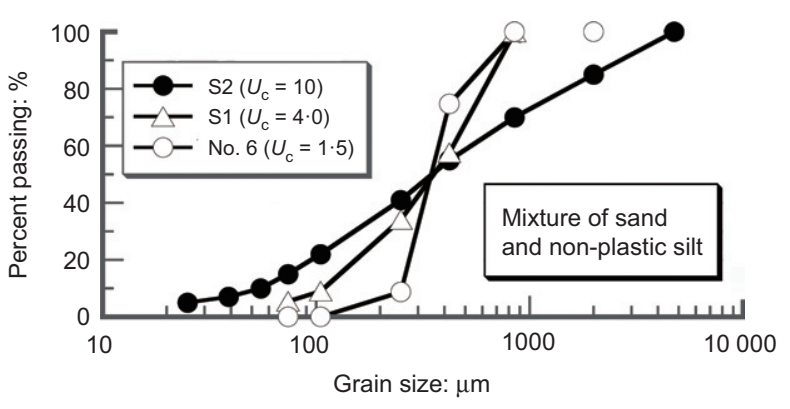

Fig. 20. Particle size distribution of tested sand

Table 1. Physical properties of tested sand

\begin{tabular}{l|c|c|c|c|c}
\hline Name & $e_{\max }$ & $e_{\min }$ & $D_{50}: \mu \mathrm{m}$ & $U_{\mathrm{c}}$ & $\begin{array}{c}\text { Passing of No. 200 } \\
(0.075 \mathrm{~mm}) \text { sieve: } \%\end{array}$ \\
\hline No. 6 & $1 \cdot 023$ & 0.638 & 356 & $1 \cdot 51$ & 0 \\
S1 & 0.907 & 0.480 & 365 & $4 \cdot 01$ & $5 \cdot 4$ \\
S2 & 0.756 & $0 \cdot 361$ & 359 & $10 \cdot 2$ & 15 \\
\hline
\end{tabular}

silica sands; see Fig. 20 and Table 1. These sands are non-plastic and have nearly identical $D_{50}$ size, while the uniformity coefficient $\left(U_{\mathrm{c}}\right)$ is different. Because the fines content has no cohesion, the present study addresses the effect of non-plastic fines.

\section{Test results}

Figure 21 shows two pictures of grains of sand S1 $\left(U_{\mathrm{c}}=4 \cdot 0\right)$ on the third and fourth days of the experiment. The two photographs were compared to find out the change of grain locations. It can be seen that the grain in the circle changed its position, showing the occurrence of dislocation. The dislocation continued for weeks but gradually calmed down.

Figure 22 indicates the temporal increase of the number of dislocated grains for different relative densities $\left(D_{\mathrm{r}}\right)$ and uniformity coefficients $\left(U_{\mathrm{c}}\right)$. Because the initial packing immediately after sample preparation was unstable, the first 3 days were excluded from the study. When $U_{\mathrm{c}}$ is constant, looser sand exhibits more particle dislocations than denser sand because the grain structure of loose sand is less stable. On the other hand, the sand with greater $U_{\mathrm{c}}$ developed more significant dislocations. This is consistent with the general perception that sands with more fines achieve more significant ageing than uniformly grained sand (Wakamatsu et al., 1991; Sawada et al., 2005).

\section{Liquefaction tests}

Cyclic undrained triaxial tests were conducted on the same sands in order to show the relationship between the fines content, the rate of dislocation and the ageing of liquefaction resistance. All the specimens with diameter of $5 \mathrm{~cm}$ and $10 \mathrm{~cm}$ high were prepared by air pluviation in a rigid cylinder and then were subjected to one-dimensional consolidation under $25 \mathrm{kPa}$ of overburden. The duration of consolidation varied from 1 to 64 days. After consolidation, specimens were set in a triaxial device to be consolidated isotropically under $25 \mathrm{kPa}$. Then, cyclic undrained tests were performed.

Figure 23 compares the liquefaction resistance of tested specimens. Tests on $\mathrm{S} 1$ sand failed and are not presented here. While the sand with more non-plastic fines $\left(U_{\mathrm{c}}=10\right)$ is weaker against liquefaction (greater uniformity coefficient in 

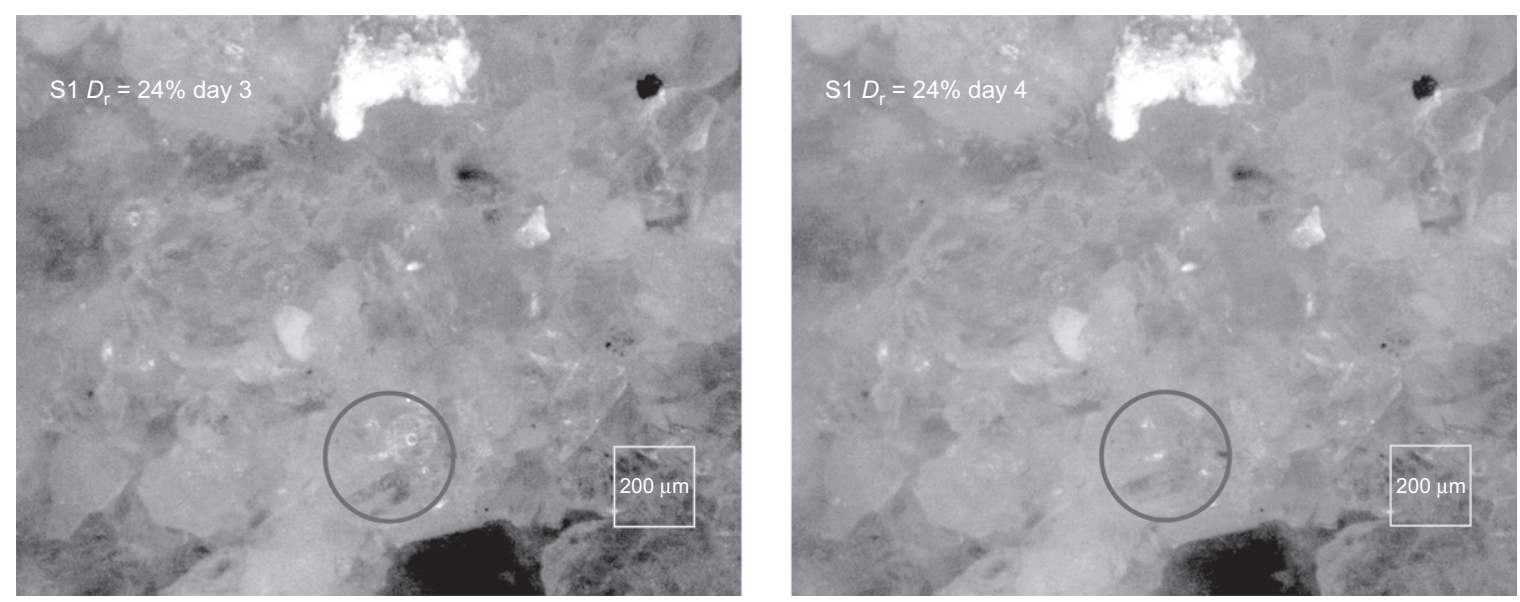

Fig. 21. Particle dislocation during 1-day time interval

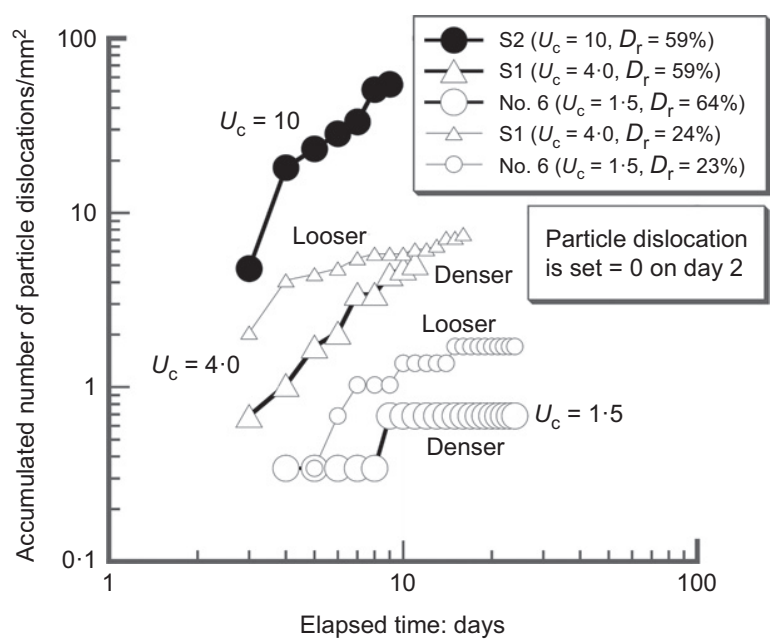

Fig. 22. Relationship between particle dislocation and relative density

Fig. 23), as has been reported elsewhere (Towhata et al. (2013), among others), this sand increased liquefaction resistance with time more rapidly than sand with less fines $\left(U_{\mathrm{c}}=1 \cdot 5\right)$. This finding is consistent with Fig. 22, where more dislocation occurred in sand with higher uniformity coefficient. Thus, the hypothesis in Fig. 19 is promising. As dislocation occurs slowly with time, it is a microscopic perception of soil creep. Finally, the higher rate of dislocation for greater fines content implies that soils with greater fines content can develop higher liquefaction resistance as current design codes specify.

\section{CONCLUSION}

Earthquake damage histories indicate that subsoil liquefaction has occurred in young sandy deposits. Because more aged sand did not liquefy, it is possible that ageing increases the liquefaction resistance of loose sand over hundreds of years. To quantitatively evaluate the ageing, the behaviour of sandy subsoil during past earthquakes was investigated. Consequently, the following conclusions were drawn.

(a) The 2011 Tohoku earthquake revealed that liquefaction occurs more profoundly in younger subsoil.

(b) Borehole data and the intensity of seismic shaking were analysed to calculate the factor of safety against liquefaction, $F_{\mathrm{L}}$, for different age groups. The assessed

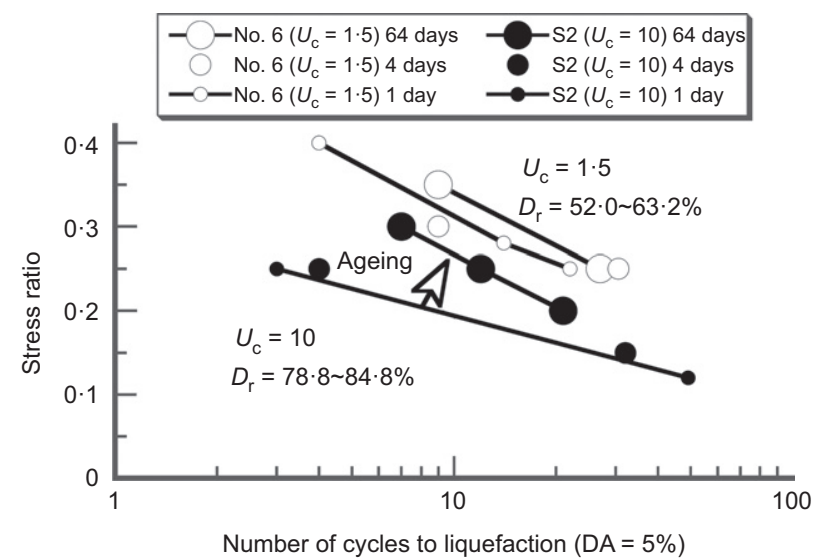

Fig. 23. Liquefaction resistance increasing with consolidation time $\left(U_{\mathrm{c}}=1.5\right.$ and 10)

$F_{\mathrm{L}}$ at liquefied and unliquefied sites were compared against the age of soil to show that more aged sand did not liquefy in spite of $F_{\mathrm{L}}$ less than unity.

(c) This suggests that more aged sand has additional liquefaction resistance, which is called the ageing effect.

(d) For practice, it is proposed that soil older than 400 years has $40 \%$ greater resistance against liquefaction than what SPT- $N$ implies in the current seismic design codes. Note that this proposal is of reasonable conservatism.

(e) Laboratory tests were conducted to verify a hypothetical mechanism and results indicate that sand grains under static load dislocate with time and fill the larger voids. As a result, big voids, which are mechanical weakness of grain structure, disappear and a more compacted, stable, granular structure is developed.

\section{ACKNOWLEDGEMENTS}

The present study was supported financially by Tokyo Gas Company. Important subsoil data were provided by the Geotechnical Database for Kanto Region by JGS, Geotechnical Database by the Ministry of Land, Infrastructure, Transport and Tourism, Kansai Geo-informatics Database, Geoenvironmental Information Bank of Chiba and Dr Seiji Suwa. The intensity of ground motion was obtained from K-Net of the National Research Institute for Earth Science and Disaster Prevention. Dr Way Way Sim of Imperial College London kindly assisted with 

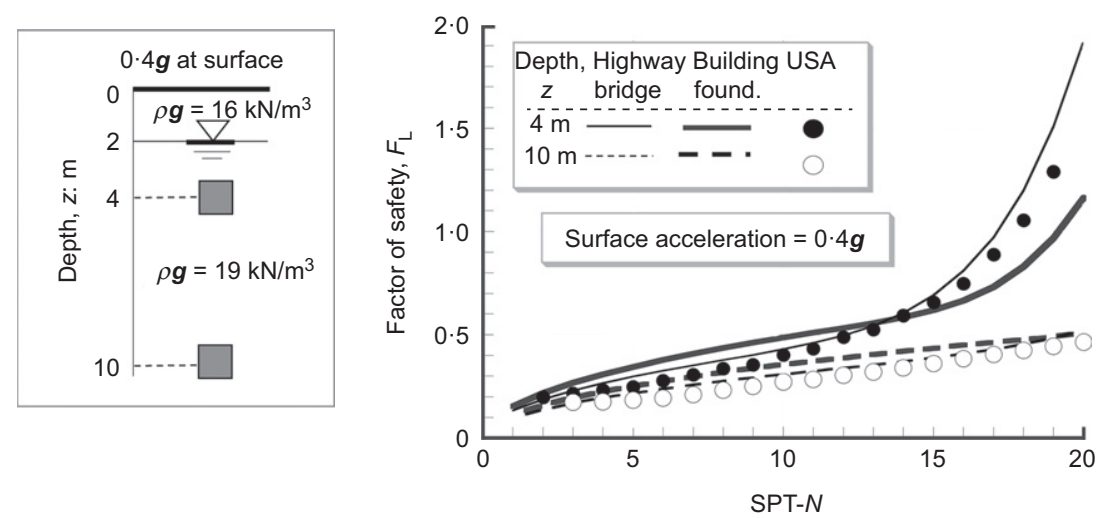

Fig. 24. Comparison of two Japanese codes with US practice for liquefaction risk assessment

editing the text. This various support and assistance is greatly appreciated by the authors.

\section{APPENDIX. BRIEF VIEW OF HIGHWAY BRIDGE DESIGN CODE AND RECOMMENDATIONS FOR DESIGN OF BUILDING FOUNDATIONS}

Liquefaction risk assessed by the two Japanese codes used in this paper, which are the Highway bridge design code (JRA, 2012) and Recommendations for design of building foundations (AIJ, 2001), are compared with recent US practice (Idriss \& Boulanger, 2006). The assumed soil condition is made of clean sand (fines content = $0 \%$ ) and the depth of interest, $z$, is either $4 \mathrm{~m}$ or $10 \mathrm{~m}$, while the groundwater table is located at $2 \mathrm{~m}$ depth; see Fig. 24. The design earthquake has the maximum acceleration of $0 \cdot 4 \mathrm{~g}$ and its magnitude is $8 \cdot 0$. The energy efficiency of Japanese SPT practice was set equal to $70 \%$ by referring to Seed et al. (1985). By varying SPT- $N$, the change of $F_{\mathrm{L}}$ was plotted in Fig. 24 where three examined codes are consistent with one another, irrespective of the effective stress level, except for the range of SPT- $N>17$ at shallow depth.

\section{NOTATION}

$C_{1}, C_{2}$ parameters for fines-content effect

$D_{\text {r }}$ relative density

$D_{50}$ mean grain size of sand

$F_{\mathrm{c}}$ fines content

$F_{\mathrm{L}}$ factor of safety of soil against liquefaction

$F_{\mathrm{L}, \max }$ maximum value of $F_{\mathrm{L}}$ in soil profile at sites without

liquefaction

$F_{\mathrm{L} \text {,min }}$ minimum value of $F_{\mathrm{L}}$ in soil profile at sites of liquefaction

g gravitational acceleration

$L \quad$ seismic load

$M_{\mathrm{w}}$ moment magnitude of earthquake

$N \quad$ SPT blow counts

$R$ liquefaction resistance of sand

$U_{\mathrm{c}} \quad$ uniformity coefficient of grain distribution of sand

$\sigma_{\mathrm{v}}^{\prime} \quad$ effective vertical stress prior to earthquake shaking

\section{REFERENCES}

AIJ (Architectural Institute of Japan) (2001). Recommendations for the design of building foundations, pp. 61-72. Tokyo, Japan: Architectural Institute of Japan (in Japanese).

Arango, I., Lewis, M. R. \& Kramer, C. (2000). Updated liquefaction potential analysis eliminates foundation retrofitting of two critical structures. Soil Dynam. Earthquake Engng 20, No. 1-4, $17-25$.

Baxter, C. D. P. \& Mitchell, J. K. (2004). Experimental study on the aging of sands. J. Geotech. Geoenviron. Engng, ASCE 130, No. 10, 1051-1062.

Dobry, R., Abdoun, T., Stokoe, K. H., II, Moss, R. E. S., Hatton, M. \& El Ganainy, H. (2015). Liquefaction potential of recent fills versus natural sands located in high-seismicity regions using shear-wave velocity. J. Geotech. Geoenviron. Engng, ASCE 141, No. 3, 04014112-1-04014112-13.

Goto, S. (1995). Liquefaction characteristics of sand undergoing high-temperature curing (Part 2). Proceedings of the 30th Japan national conference on geotechnical engineering, Kanazawa, Japan, pp. 859-860 (in Japanese).

Goto, S., Shamoto, Y. \& Tamaoki, K. (1987). Dynamic properties of undisturbed sample by in-situ frozen. Proceedings of the 8th Asian regional conference of soil mechanics and foundation engineering, Kyoto, Japan, vol. 1, pp. 233-236.

Goto, S., Suzuki, Y., Nishio, S. \& O-oka, H. (1992). Mechanical properties of Tone-river gravel obtained by In-situ freezing method. Soils Found. 32, No. 3, 15-25.

Hamada, T., Suwa, S., Iwasaki, Y. Kurazono, M. \& Tsuda, K. (1997). Seismic damage by liquefaction at Tsukiji area in Amagasaki (Part 2). Proceedings of annual congress of Japan Association for Quaternary Research, Sapporo, Japan, pp. 148-149 (in Japanese).

Hatanaka, M., Sugimoto, M. \& Suzuki, Y. (1985). Liquefaction resistance of two alluvial volcanic soils sampled by in situ freezing. Soils Found. 25, No. 3, 49-63.

Hatanaka, M., Suzuki, Y., Kawasaki, T. \& Endo, M. (1988). Cyclic undrained shear properties of high quality undisturbed Tokyo gravel. Soils Found. 28, No. 4, 57-68.

Hayati, H. \& Andrus, R. D. (2009). Updated liquefaction resistance correction factors for aged sands. J. Geotech. Geoenviron. Engng, ASCE 135, No. 11, 1683-1692.

Heidari, T. \& Andrus, R. D. (2012). Liquefaction potential assessment of Pleistocene beach sands near Charleston, South Carolina. J. Geotech. Geoenviron. Engng, ASCE 138, No. 10, 1196-1208.

Hori, T., Yamashita, S. \& Suzuki, T. (2002). Shear wave velocity and liquefaction strength of freezing sampling and reconstituted specimens. Proc. JSCE Hokkaido Chapter JSCE-Hokkaido 58, 526-529 (in Japanese).

Idriss, I. M. \& Boulanger, R. W. (2006). Semi-empirical procedures for evaluating liquefaction potential during earthquakes. Soil Dynam. Earthquake Engng 26, No. 2-4, $115-130$.

Inada, M. (1960). Interpretation of Swedish weight sounding. Monthly Mag. Jap. Geotech. Soc. 8, No. 1, 13-18.

Ishihara, K. \& Yamazaki, F. (1980). Cyclic simple shear tests on saturated sand in multi-directional loading. Soils Found. 20, No. 1, 45-59.

JRA (Japan Road Association) (2012). Earthquake resistant design. Highway bridge design code, vol. V. Tokyo, Japan: Japan Road Association (in Japanese).

Kiyota, T., Koseki, J., Sato, T. \& Kuwano, R. (2009). Aging effects on small strain shear moduli and liquefaction properties of in-situ frozen and reconstituted sandy soils. Soils Found. 49, No. 2, 259-274.

Kokusho, T., Nagao, Y., Ito, F. \& Fukuyama, T. (2012). Aging effect on sand liquefaction observed during the 2011 earthquake and basic laboratory studies. Proceedings of international symposium: Engineering lessons learned from the 2011 Great East Japan earthquake, Tokyo, Japan, pp. 759-770. 
Kondo, Y. (2013). Effects of sand ageing on liquefaction resistance in young reclaimed land in Urayasu City. Masters thesis, Civil Engineering Department, University of Tokyo, Tokyo, Japan (in Japanese).

Kusunoki, K., Nakazawa, H., Sugano, T., Okubo, Y., Kiku, H. \& Fujita, D. (2013). Laboratory experiment on long-term recovery of liquefied ground state. Proc. $J S C E$ (A1) 69, No. 4, L326-L336 (in Japanese).

Leon, E., Gasman, S. L. \& Talwani, P. (2006). Accounting for soil aging when assessing liquefaction potential. J. Geotech. Geoenviron. Engng, ASCE 132, No. 3, 363-377.

Lewis, M., Arango, I. \& McHood, M. (2008). Site characterization philosophy and liquefaction evaluation of aged sands - a Savannah River site and Bechtel perspective. In From research to practice in geotechnical engineering (eds J. E. Laier, D. K. Crapps and M. H. Hussein), Geotechnical Special Publication 180, pp. 540-558. Reston, VA, USA: American Society of Civil Engineers.

Massarsch, K. R. \& Fellenius, B. H. (2002). Vibratory compaction of coarse-grained soils. Can. Geotech. J. 39, No. 3, 695-709.

Matsuo, O. (2004). Simplified procedure for assessing liquefaction potential of soils in the specifications for highway bridges. Proc. JSCE 757, No. III-66, 1-20 (in Japanese).

Mesri, G., Feng, T. W. \& Benak, J. M. (1990). Postdensification penetration resistance of clean sands. J. Geotech. Engng, ASCE 116, No. 7, 1095-1115.

Mitchell, J. K. \& Solymer, Z. V. (1984). Time-dependent strength gain in freshly deposited or densified sand. J. Geotech. Engng, ASCE 110, No. 11, 1559-1576.

Mulilis, J. P., Mori, K., Seed, H. B. \& Chan, C. K. (1977). Resistance to liquefaction due to sustained pressure. Proc. ASCE 103, No. GT7, 793-797.

Nagase, H., Shimizu, K., Hiro-oka, A., Mochinaga, S. \& Ohta, M. (1999). Increase in liquefaction strength of sandy soils due to aging. Proceedings of the 34th Japan national conference on geotechnical engineering, Tokyo, Japan, pp. 987-988 (in Japanese).

Roy, D. (2008). Coupled use of cone tip resistance and small strain shear modulus to assess liquefaction potential. J. Geotech. Geoenviron. Engng, ASCE 134, No. 4, 519-530.

Sawada, R., Kawanishi, T. \& Ohki, M. (2005). Strength ratio causing liquefaction of diluvial ground. Proceedings of the 28th JSCE earthquake engineering symposium, Tokyo, Japan, pp. 186-189 (in Japanese).

Schmertmann, J. H. (1991). The mechanical aging of soils. J. Geotech. Engng, ASCE 117, No. 9, 1288-1330.

Seed, H. B. (1979). Soil liquefaction and cyclic mobility evaluation for level ground during earthquakes. J. Geotech. Engng, ASCE 105, No. 2, 201-255.

Seed, H. B. \& Idriss, I. M. (1982). Ground motions and soil liquefaction during earthquakes, Monograph series. Berkeley, CA, USA: Earthquake Engineering Research Institute, University of California.

Seed, H. B., Pyke, R. M. \& Martin, G. R. (1978). Effect of multidirectional shaking on pore pressure. Proc. ASCE 111, No. GT1, 27-44.

Seed, H. B., Tokimatsu, K., Harder, L. \& Chung, R. M. (1985). Influence of SPT procedures in soil liquefaction resistance evaluations. J. Geotech. Engng, ASCE 111, No. 12, 1425-1445.

Seki, S., Mori, S. \& Tachibana, H. (1992). Ageing effect in liquefaction resistance of sand by undisturbed sampling at archaeological site in Yuhigahama, Kamakura. Proceedings of the 47th annual convention - JSCE, Sendai, Japan, pp. 292-293 (in Japanese).

Shintaku, Y. \& Towhata, I. (2013). Experimental validation of relationship between particle movement and ageing effect in liquefaction resistance of sand. Proceedings of international symposium on advances in foundation engineering (ISAFE 2013), Singapore, pp. 139-144.

Skempton, A. W. (1986). Standard penetration test procedures and the effects in sands of overburden pressure, relative density, particle size, ageing and overconsolidation. Géotechnique 36, No. 3, 425-447, http://dx.doi.org/10.1680/geot.1986.36.3.425.

Tatsuoka, F., Iwasaki, T., Tokida, K. Yasuda, S., Hirose, M., Imai, T. \& Kon-no, M. (1980). Standard penetration tests and soil liquefaction potential evaluation. Soils Found. 20, No. 4, 95-111.

Tatsuoka, F., Kato, H., Kimura, M. \& Pradhan, T. B. S. (1988). Liquefaction strength of sands subjected to sustained pressure. Soils Found. 28, No. 1, 119-131.

Tokimatsu, K. \& Yoshimi, Y. (1983). Empirical correlation of soil liquefaction based on SPT N-value and fines content. Soils Found. 23, No. 4, 56-74.

Towhata, I., Kiyota, T. \& Konagai, K. (2012). Ongoing study on protection of personal houses from liquefaction problems. ISSMGE Bull. 6, No. 6, 8-17.

Towhata, I., Gunji, K., Albert, H. Y. \& Yamada, S. (2013). Laboratory tests on cyclic undrained behavior of loose sand with cohesionless silt and its application to assessment of seismic performance of subsoil. In Soil liquefaction during recent large-scale earthquakes (eds R. P. Orense, I. Towhata and N. Chouw), pp. 79-94. Boca Raton, FL, USA: CRC Press, Taylor \& Francis Group.

Towhata, I., Maruyama, S., Kasuda, K., Koseki, J., Wakamatsu, K., Kiku, H., Kiyota, T., Yasuda, S., Taguchi, Y., Aoyama, S. \& Hayashida, T. (2014). Liquefaction in Kanto Region during the East-Japan gigantic earthquake on March 11, 2011. Soils Found. 54, No. 4, 859-873.

Towhata, I., Goto, S., Taguchi, Y., Hayashida, T., Shintaku, Y. \& Hamada, Y. (2015). On ageing of liquefaction resistance of sand. In Proceedings of the 15 Asian regional conference on soil mechanics and geotechnical engineering, Fukuoka, Japan, Japanese Geotechnical Society Special Publication no. 2, pp. 800-805. Tokyo, Japan: Japanese Geotechnical Society.

Wakamatsu, K. (2000). Liquefaction history, 416-1997, in Japan. Proceedings of the 12th WCEE, Auckland, New Zealand, paper no. 2270 .

Wakamatsu, K. (2011). Map of liquefaction history in Japan from $A D 745$ to 2008 . Tokyo, Japan: University of Tokyo Press.

Wakamatsu, K., Hamada, M., Yasuda, S., Yoshida, N. \& Yoshiwara, T. (1991). Liquefaction history of fill land Part 2: case study on 1983 the Nihonkai-chubu earthquake and the 1987 Chibaken-toho-oki earthquake. Proceedings of Japan national conference on soil mechanics and foundation engineering, Nagano, Japan, pp. 861-864 (in Japanese).

Wichtmann, T. A., Niemunis, A., Triantafyllidis, Th. \& Poblete, M. (2005). Correlation of cyclic preloading with the liquefaction resistance. Soil Dynam. Earthquake Engng 25, No. 12, 923-932.

Yasuda, S. \& Ishikawa, K. (2012). Several features of liquefaction-induced damage to houses and buried lifelines during the 2011 great east Japan earthquake. Proceedings of international symposium on earthquake lessons learned from the 2011 Great East Japan earthquake, Tokyo, Japan, pp. $825-836$.

Yoshimi, Y., Tokimatsu, K., Kaneko, O. \& Makihara, Y. (1984). Undrained cyclic shear strength of a dense Niigata sand. Soils Found. 24, No. 4, 131-145.

Youd, T. L. \& Hoose, S. N. (1977). Liquefaction susceptibility and geologic setting in dynamics of soil and soil structures. Proceedings of the 6th WCEE, New Delhi, India, pp. 2189-2194.

Youd, T. L. \& Perkins, D. M. (1978). Mapping liquefaction-induced ground failure potential. J. Geotech. Engng, ASCE 104, No. 4, 433-446. 